\title{
How the beyond Budgeting Management Model Enables Lean Thinking and the Agile Organization
}

\author{
Peter G. Bunce \\ BBRT, 745 Ampress Lane, Lymington, Hampshire SO41 8LW, UK \\ peterbunce@bbrt.org
}

\begin{abstract}
Lean thinking has been around for decades, yet relatively few organizations have adopted and benefited from its ideas to the fullest extent. Even fewer organizations have gone on to become both lean and agile. As the evidence for such radical improvements is so compelling you have to wonder why. Most organizations implement lean thinking as a series of tools and have no concept of agility. Effective lean thinking and agility require organizations to push decision-making and responsibility down to the self-managed teams, yet the way most organizations are designed and managed inhibits changing from hierarchies and command-and-control to these self-managed teams.

This presentation briefly outlines why we need to change from the traditional command-and-control management model to the Beyond Budgeting learn-and-adapt management model. It examines the basic requirements of lean thinking and agility why this learn-and-adapt model is necessary to enable lean thinking and agility to realise their full potential. It explores the visions and principles of the Beyond Budgeting management model, with examples from companies that have adopted many of these principles. Finally it explores some of the practical steps for successful implementation and change management. Peter Bunce is a Director of the Beyond Budgeting Round Table (BBRT), an international shared learning network dedicated to helping organizations move beyond command-and-control. His background is in manufacturing engineering.
\end{abstract}

